\title{
MODELAGEM DA ILHA DE CALOR URBANA DE SUPERFÍCIE UTILIZANDO REGRESSÃO GEOGRAFICAMENTE PONDERADA (GWR)
}

\author{
ALVES, Elis Dener Lima - elis.alves@ifgoiano.edu.br \\ Instituto Federal de Educação, Ciência e Tecnologia Goiano / IF Goiano
}

GALVANI, Emerson - egalvani@usp.br
Universidade de São Paulo / USP

\author{
Submetido em: 25/09/2020 \\ Aceito para publicação em: $18 / 05 / 2021$ \\ Publicado em: 08/06/2021 \\ DOI: http://dx.doi.org/10.5380/abclima.v28i0.76786
}

\begin{abstract}
RESUMO: A ilha de calor urbana de superfície (ICUS) é o fenômeno climático urbano mais evidente das transformações provocadas pela ação humana, e, por conseguinte, das alterações climáticas em escala local. Diante disso, essa pesquisa teve como objetivo modelar a ICUS por meio de modelos estacionários (MQO) e não estacionários (GWR) utilizando variáveis Altitude, Índice de Posição Topográfica - IPT, Normalized Difference Vegetation Index - NDVI, Índice da Diferença Normalizada de Água - NDWI e Índice de Urbanização - IU da cidade de São Carlos, São Paulo, Brasil. Os resultados evidenciaram que o modelo GWR explicou mais satisfatoriamente a variabilidade da ICUS que o modelo MQO, explicando $90 \%$ da variação da ICUS no verão, enquanto que o MQO explicou $79 \%$. Os valores de AICc indicaram, também, superioridade do modelo GWR. As informações obtidas pelo modelo não estacionário poderão facilitar a implementação de medidas mitigadoras da ICUS. O modelo GWR mostrou-se ser eficiente para modelar a ICUS em cidade média, portanto, sugere-se que esse modelo seja utilizado em pequenas e grandes cidades brasileiras para que possa ser validado em cidades com diferentes características espaciais.
\end{abstract}

PALAVRAS-CHAVE: Clima Urbano, Modelagem Espacial, Sazonalidade, Planejamento.

MODELING OF THE URBAN SURFACE HEAT ISLAND USING GEOGRAPHICALLY WEIGHTED REGRESSION (GWR)

ABSTRACT: The surface urban heat island (ICUS) is the most evident urban phenomenon of the transformations caused by human action, and consequently, of climatic changes on a local scale. Therefore, this research aimed to model the ICUS using stationary (MQO) and non-stationary (GWR) models using natural and anthropic variables (Altitude, Topographic Position Index - IPT, Normalized Difference Vegetation Index NDVI, Difference Index Normalized Water - NDWI and Urbanization Index - IU) in the city of São Carlos, São Paulo, Brazil. The results showed that the GWR model explained ICUS variability more satisfactorily than the MQO model, explaining $90 \%$ of the variation of ICUS in the summer, while the MQO explained $79 \%$. The AICc values also indicated the superiority of the GWR model. The information obtained by the non-stationary model may facilitate the implementation of ICUS mitigation measures. The GWR model proved to be efficient to model ICUS in a medium city, therefore, it is suggested that this model be used in small and large Brazilian cities so that it can be validated in cities with different spatial characteristics..

KEYWORDS: Urban Climate, Spatial Modeling, Seasonality, Planning.

\section{INTRODUÇÃO}

As preocupações com as condições climáticas e melhoria da qualidade de vida da população das metrópoles levaram vários estudiosos a realizarem pesquisas sobre essa temática (ALCOFORADO et al., 2009; ALVES; LOPES, 2017; AMORIM; DUBREUIL; CARDOSO, 2015; COUTTS; BERINGER; TAPPER, 
2007; LOMBARDO, 1985; OKE, 1981; SOUCH; GRIMMOND, 2006; TARIFA; AZEVEDO, 2001; ZOULIA; SANTAMOURIS; DIMOUDI, 2009).

Os estudos realizados na atmosfera urbana têm mostrado que as cidades geram um clima próprio, o chamado clima urbano, e que esse é o resultado da interferência de todos os fatores que se processam sobre a camada limite urbana e que agem alterando o clima em escala local ou regional (MONTEIRO, 1976). Nas cidades, as modificações da ocupação do solo decorrem da concentração de construções, impermeabilização com o asfaltamento de ruas e avenidas, aumento do fluxo de pessoas e automóveis, além da diminuição da vegetação, fazendo com que essas alterações tenham uma repercussão não só em nível local, mas em dimensão regional, dependendo do tamanho da respectiva área urbana (ALVES; ANJOS; LOPES, 2017; ALVES; BIUDES, 2012; GARTLAND, 2012; TARIFA; AZEVEDO, 2001).

A característica mais proeminente do clima urbano é o efeito da ilha de calor urbana (ICU), na qual a temperatura de superfície é um importante parâmetro para analisá-lo (BALA et al., 2018; GÉMES; TOBAK; LEEUWEN, 2016; MA; KUANG; HUANG, 2010). A ilha de calor urbana é geralmente avaliada de duas formas, tradicionalmente, a ICU tem sido mensurada pelas observações terrestres por meio de transectos móveis ou redes de estações meteorológicas (AMORIM; DUBREUIL; CARDOSO, 2015; MINAKI; AMORIM, 2014; VOOGT; OKE, 2003), com o avanço de novas tecnologias geoespaciais, os pesquisadores tem utilizado, cada vez mais as imagens de satélite para estimar a ilha de calor urbana de superfície (ICUS) (ALVES, 2016a; ALVES; BIUDES, 2013; LOPES et al., 2013; TARIFA; AZEVEDO, 2001).

Comparado ao método tradicional, o sensoriamento remoto por satélite fornece uma maneira direta e consistente para examinar o ambiente térmico das cidades, podendo se obter uma cobertura espacial contínua de grandes áreas (AMORIM; DUBREUIL; CARDOSO, 2015; LOMBARDO, 1985; NICHOL; J.E; NICHOL, 1998; XU, 2009; XU; QIN; WAN, 2010), entretanto, conforme elucidado por Alcoforado et al., (2007) e Lucena (2013), a ilha de calor urbana (ICU) difere da ilha de calor urbana de superfície (ICUS), pois a primeira referese a diferença da temperatura do ar da área urbana em relação à rural, enquanto que a segunda refere-se a temperatura da superfície.

A ICU e a ICUS não causam, somente, elevada temperatura no verão e aumento no consumo de energia para arrefecimento, mas também pode levar a sérios problemas no conforto térmico das pessoas e até mesmo na saúde (ABREU-HARBICH; LABAKI; MATZARAKIS, 2013; ALI-TOUDERT et al., 2005; GABRIEL; ENDLICHER, 2011; TAN et al., 2010). Portanto, mitigar a ICU é fundamental.

Os estudos das ilhas de calor urbanas têm se mostrado um instrumento importante para a gestão do espaço urbano. A espacialização das diferenças das temperaturas intra-urbanas e rurais próximas pode oferecer subsídios para amenizar a magnitude das ilhas de calor (AMORIM; CARDOSO, 2015). As simulações das ilhas de calor urbanas têm sido utilizadas em inúmeros trabalhos (AMORIM; JUNIOR, 2016; MIHALAKAKOU et al., 2002; SAITOH; SHIMADA; HOSHI, 1996; STEWART; OKE; KRAYENHOFF, 2014). As simulações, desde que comparadas com dados reais ou baseadas em estudos e observações de outras pesquisas, podem fornecer perspectivas ao reordenamento ao território. 
Diversos pesquisadores desenvolveram equações, com diferentes fatores, para modelar a ilha de calor urbana, tais como: Coseo e Larsen (2014); Oke (1973), Souza et al., (2010); Tan e Li (2015); Torok et al., (2001); Amorim et al., (2015); Luo e Peng et al., (2016); Ivajnšič et al., (2014) e Alves et al., (2016b). Unger et al.,(2011) relataram que estudos mais recentes sobre as características espaciais da ICUS são baseados em algoritmos de interpolação multidimensional, sendo os modelos baseados em regressões globais, como os Mínimos Quadrados Ordinários (MQO) os mais frequentemente utilizados. Embora as relações locais de regressão multivariada estejam relativamente bem estabelecidas, as análises estatísticas da maioria dos estudos têm sido geralmente não espaciais, negligenciando a informação de localização geográfica associada a cada amostra (FOODY, 2003).

Dutilleul e Legendre (1993) apontaram que os padrões e processos geográficos e ecológicos observados na natureza tendem a ser espacialmente variáveis. Apesar disso, esse fenômeno é muitas vezes referido como um fenômeno não espacial (IVAJNŠIČ; KALIGARIČ; ŽIBERNA, 2014). A análise de regressão múltipla, como o modelo de MQO, baseia-se na suposição de independência das observações, resultando na incapacidade de captar a dependência espacial dos dados georreferenciados (FOODY, 2003; IVAJNŠIČ; KALIGARIČ; ŽIBERNA, 2014; LI et al., 2010). Brunsdon e Fotheringham em 2010 desenvolveram uma técnica de regressão local, chamada de regressão geograficamente ponderada (GWR) que pressupõe que o espaço é heterogêneo ou não-estacionário e a relação entre as variáveis dependentes e independentes assume padrões mais ou menos regionalizados (BRUNSDON; FOTHERINGHAM; CHARLTON, 2010).

Quantificar e modelar a ICUS e suas variáveis independentes são passos importantes para melhorar a qualidade de vida das pessoas que residem nas cidades e alcançar a sustentabilidade urbana em todos os tipos de cidades (LOPES et al., 2013). Enquanto a maioria dos estudos sobre ICU e ICUS se concentra em grandes cidades, o objetivo geral dessa pesquisa foi modelar a intensidade da ICUS na cidade de São Carlos - São Paulo, utilizando modelos estacionários (MQO) e não estacionários (GWR).

\section{2. ÁREA DE ESTUDO}

O município de São Carlos, localizado no estado de São Paulo (figura 1), é uma região de transição entre os biomas do Cerrado e da Mata Atlântica. O clima é controlado por massas equatoriais, tropicais (MONTEIRO, 1973) e polares. A sazonalidade é bem definida, com períodos secos distribuídos pelos meses de abril a setembro e úmidos de outubro a março, com temperatura média mensal de $20,5{ }^{\circ} \mathrm{C}$, as maiores temperaturas médias mensais ocorrem em fevereiro $\left(23^{\circ} \mathrm{C}\right)$ e janeiro $\left(22,9{ }^{\circ} \mathrm{C}\right)$, enquanto que as menores temperaturas médias ocorrem em julho $\left(16,9^{\circ} \mathrm{C}\right)$ e junho $\left(17^{\circ} \mathrm{C}\right)$ (EMBRAPA, 2019). A precipitação em São Carlos possui complexa variabilidade interanual, a média pluviométrica é $1528,1 \mathrm{~mm}$ com desvio padrão de $288,8 \mathrm{~mm}$, entretanto, no município de São Carlos podem ocorrer excepcionalidades pluviométricas: a precipitação mínima registrada é $1143,4 \mathrm{~mm}$ enquanto que a máxima é 2486,7 mm (NEVES et al., 2016). 
O município de São Carlos está geomorfologicamente localizado na borda oeste das Cuestas Basálticas, próximo ao Planalto Ocidental e a Depressão Periférica (ALMEIDA, 1964). Dessa maneira, o relevo do município de São Carlos é constituído de mesas e morros isolados, resultado de intensa erosão provocada pelos rios, que entalham profundamente o planalto. A altimetria do município apresenta uma variação de 480 metros, a menor altitude, $520 \mathrm{~m}$, é observada próxima ao Rio Mogi-Guaçu. A maior altitude atinge $1000 \mathrm{~m}$ na região sudeste do município. Na área urbana as menores altitudes estão em torno de 775 m, localizadas em vales a oeste da área urbana, enquanto que os locais mais elevados estão situados a leste, em planalto que ultrapassa os 910 $\mathrm{m}$ de altitude (BARBOSA, 2009).

Os solos do município de São Carlos apresentam elevada correlação com as formas de relevo e litologia. Nota-se, dessa forma, a presença de solos predominantemente argilosos nas cotas mais elevadas; solos rasos e afloramento de rochas nas escarpas; e solos de textura média (teor de argila entre 15 e 35\%) nas áreas com altitudes menores. Nestas últimas, verifica-se, ainda, extensas áreas de solos arenosos e profundos. Portanto, O município de São Carlos é caracterizado por solos de elevada permeabilidade, constituído, em sua maioria, por zonas de solo latossolo-vermelho-amarelo e de areia quartzosa profunda, com característica arenosa (BARBOSA, 2009).

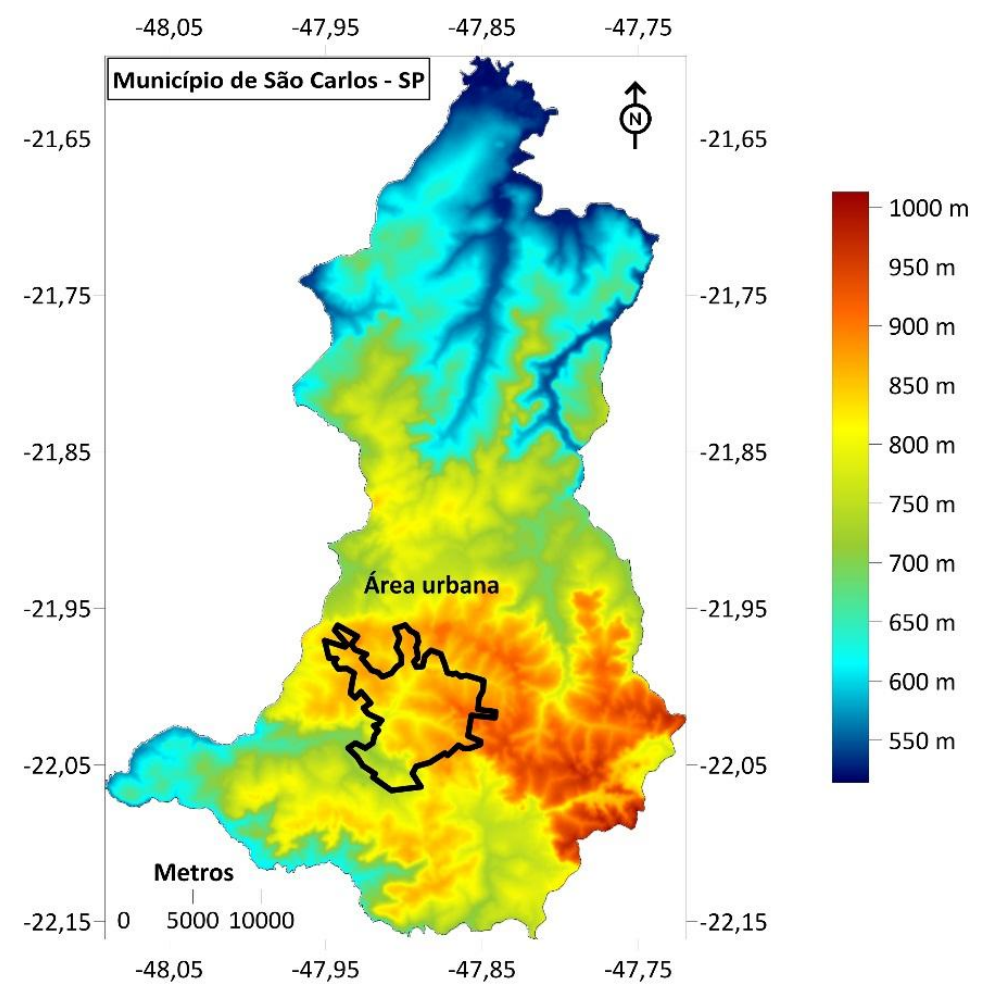

Figura 1 - Mapa hipsométrico do município de São Carlos.

A vegetação original da região é o cerrado, caracterizada por formação florestal herbáceo-lenhosa, herbáceo-arbustiva, com árvores perenifólias (BARBOSA, 2009). Esse tipo de vegetação está associado aos terrenos arenosos de topografia quase plana que se estendem ao norte, até as barrancas do rio 
Mogi-Guaçu e, ao sul, até as bordas do vale do rio Jacaré-Guaçu ((BARBOSA, 2009; BORTOLUCCI, 1991)).

Entretanto, atualmente, há pouca vegetação original. A maior parte das áreas não urbanizadas do município está ocupada por pastagens, plantações, reflorestamento e mineração (BARBOSA, 2009).

Em 2018, a população de São Carlos foi estimada em 249.415 habitantes pelo Instituto Brasileiro de Geografia e Estatística (IBGE). Entretanto, drenagem urbana, sistema rodoviário e áreas de lazer não acompanharam a expansão da cidade. $98.4 \%$ dos domicílios da cidade de São Carlos possuem esgotamento sanitário adequado, $89.2 \%$ de domicílios urbanos em vias públicas com arborização e $34.2 \%$ de domicílios urbanos em vias públicas com urbanização adequada (presença de bueiro, calçada, pavimentação e meio-fio) (BARBOSA; VECCHIA, 1996; BERE; TUNDISI, 2010), quando comparado com os outros municípios do estado, esses percentuais ficam na posição 43 de 645, 411 de 645 e 194 de 645. Já quando comparado a outras cidades do Brasil, sua posição é 46 de 5570, 1578 de 5570 e 1008 de 5570, respectivamente (IBGE, 2018). A cidade também se expandiu sem levar em conta fatores ambientais, climáticas, geológicos e topográficos (BARBOSA; VECCHIA, 1996; BERE; TUNDISI, 2010). Esse planejamento acarreta inúmeros problemas socioambientais, em relação as questões climáticas, pode gerar desconforto ambiental: elevadas temperaturas e ilhas de calor urbanas devido a urbanização desordenada.

\section{PROCEDIMENTOS METODOLÓGICOS}

O procedimento metodológico apresentado na figura 2 e discutido nos itens e subitens posteriores tem como objetivo esquematizar de forma clara e sucinta as etapas executadas nessa pesquisa. Esse procedimento metodológico foi elaborado com base em diversas pesquisas, procurando o método mais adequado para cada etapa. Para o cálculo da ICUS (variável dependente) foram necessárias seis etapas e utilizou-se das imagens do Land Remote Sensing Satellite (LANDSAT) 8 e dados Shuttle Radar Topography Mission (SRTM).

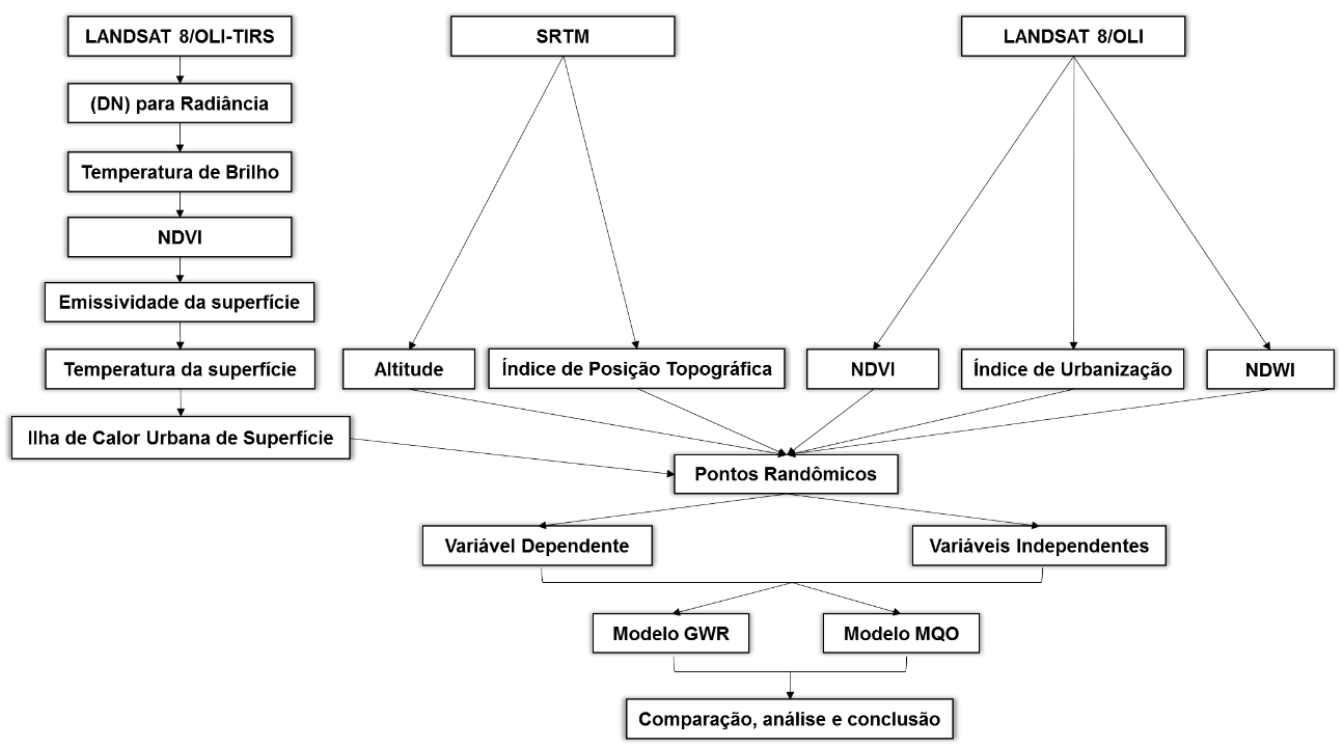

Figura 2 - Procedimento metodológico para modelar a ilha de calor urbana de superfície. 
Os sensores do satélite LANDSAT têm monitorado a Terra há mais de quatro décadas, fornecendo uma continuidade de dados durante este período (ISAYA NDOSSI; AVDAN, 2016). A primeira série deste satélite foi lançada em 1972, nomeado de LANDSAT 1. Desde então, houve um total de oito satélites LANDSAT. Entre os oito, o LANDSAT 6 falhou em atingir a órbita e caiu na Terra em 1993. Os outros satélites foram bem-sucedidos e forneceram aos pesquisadores grandes volumes de dados que foram usados em muitos estudos (ISAYA NDOSSI; AVDAN, 2016; ZHANG et al., 2009). Os dados do LANDSAT estão disponíveis livremente para download no website do United States Geological Survey (USGS) (USGS, 2016).

O recorte temporal desse estudo foi de 2015 a 2017, foram utilizadas todas as imagens disponíveis (sem cobertura de nuvens na área de estudo) para esse período. A imagem com maior cobertura de nuvens foi a do dia 23/04/2015, entretanto, essa cobertura é uma informação do quadrante da imagem, na área de estudo não havia cobertura de nuvens. As imagens são geradas no mesmo horário, com discrepância menor que 2 minutos, o que garante a comparação ao longo dos anos. Todas as imagens apresentaram ótima qualidade, com valor 9 numa escala que vai de 0 a 10, em que 0 significa péssima qualidade e 10 excelente qualidade. As condições meteorológicas em cada aquisição das imagens são observadas na tabela 1 no dia 23/04/2015 e $14 / 07 / 2016$ a umidade relativa do ar foi elevada, acima de $86 \%$, enquanto que a temperatura média do ar esteve abaixo dos $30^{\circ} \mathrm{C}$ em todas as ocasiões. A maior velocidade do vento $(7,23 \mathrm{~m} / \mathrm{s})$ foi verificada no dia $02 / 10 / 2016$.

Tabela 1 - Condições meteorológicas médias diárias na data de aquisição das imagens.

\begin{tabular}{|c|c|c|c|c|c|}
\hline Data & $\begin{array}{l}\text { Temperatur } \\
\text { a do ar }\left({ }^{\circ} \mathrm{C}\right)\end{array}$ & $\begin{array}{c}\text { Umidade } \\
\text { relativa } \\
(\%)\end{array}$ & $\begin{array}{c}\text { Velocidade do } \\
\text { vento }(\mathrm{m} / \mathrm{s})\end{array}$ & $\begin{array}{c}\text { Pressão } \\
\text { atmosférica } \\
(\mathrm{hPa})\end{array}$ & $\begin{array}{l}\text { Radiação solar } \\
\left(\mathbf{W} / \mathrm{m}^{2} / \text { dia }\right)\end{array}$ \\
\hline $23 / 04 / 2015$ & 23,2 & 87,3 & 2,50 & 927,2 & 493,69 \\
\hline $09 / 05 / 2015$ & 21,0 & 76,0 & 1,18 & 930,2 & 325,71 \\
\hline $10 / 06 / 2015$ & 21,1 & 71,8 & 0,63 & 929,2 & 304,55 \\
\hline $28 / 07 / 2015$ & 19,7 & 67,0 & 1,48 & 930,1 & 314,79 \\
\hline $13 / 08 / 2015$ & 20,7 & 55,5 & 3,22 & 931,7 & 367,37 \\
\hline 29/08/2015 & 20,9 & 73,3 & 3,54 & 932,4 & 417,01 \\
\hline $16 / 10 / 2015$ & 28,4 & 54,0 & 3,05 & 929,4 & 440,34 \\
\hline 09/04/2016 & 27,0 & 66,8 & 2,97 & 925,1 & 385,18 \\
\hline $14 / 07 / 2016$ & 20,9 & 86,5 & 3,03 & 925,4 & 302,54 \\
\hline $30 / 07 / 2016$ & 17,7 & 66,8 & 2,84 & 930,9 & 300,92 \\
\hline $02 / 10 / 2016$ & 22,7 & 57,3 & 7,23 & 929,6 & 521,31 \\
\hline $23 / 02 / 2017$ & 26,4 & 63,8 & 3,00 & 927,6 & 499,75 \\
\hline 03/09/2017 & 21,8 & 40,8 & 4,67 & 934,1 & 456,64 \\
\hline $19 / 09 / 2017$ & 23,8 & 45,0 & 4,50 & 929,8 & 420,57 \\
\hline 05/10/2017 & 27,2 & 51,5 & 3,26 & 928,4 & 426,64 \\
\hline
\end{tabular}

Normalmente a intensidade da ilha de calor urbana (ICU) é mensurada a partir das observações da temperatura do ar ao longo de transectos ou em 
estações fixas na área urbana e rural circundante (CAO et al., 2010; LOPES et al., 2013). Entretanto, a ilha de calor urbana de superfície (ICUS) adquire outro significado, por se tratar de um dado obtido por sensoriamento remoto (ALVES, 2016a). A ICUS foi calculada como sendo a diferença da temperatura de superfície de cada pixel da área urbana pela temperatura de superfície média da área rural (ALVES, 2016a; LI; MO; DAI, 2011; RASUL; BALZTER; SMITH, 2015), conforme a equação 1 .

$$
I C U S=B T_{U}-\overline{B T_{R}}
$$

Em que $B T_{U}$ é a temperatura de superfície em cada pixel da área urbana e $B T_{R}$ é a média da temperatura de superfície da área rural obtida a partir de um buffer de $1 \mathrm{~km}$ do limite urbano (figura 3). Valor positivo significa a ocorrência de ICUS, enquanto que valor negativo representa ilha de frescor urbana de superfície (IFUS). Não existe um método padronizado para se delimitar o buffer da área rural e mensurar a ICUS, por exemplo: Alves (2016a) utilizou buffer de $500 \mathrm{~m}$ para analisar a variação sazonal e espacial da intensidade ICUS em um pequeno aglomerado urbano no Brasil; Alves (2017a) utilizou buffer de $200 \mathrm{~m}$ e $500 \mathrm{~m}$ para quantificar o efeito dos cursos d'água e área verde na temperatura de superfície; Cheval e Dumitrescu (2014) usaram buffers de vários tamanhos (1 a 7 km) para analisar a ICUS de verão em Bucareste na Romênia; Rasul et al., (2015) utilizaram buffer de $10 \mathrm{~km}$ ao redor da cidade de Erbil no Curdistão iraquiano para definir a temperatura de superfície rural e Debbage e Shepherd (2015) estabeleceram um buffer de $50 \mathrm{~km}$ para estimar a intensidade da ICUS das 50 cidades mais populosas dos Estados Unidos. Portanto, não há a definição do tamanho do buffer, ele é estipulado de acordo com as especificidades da área de estudo, por isso, nessa pesquisa, levando em consideração a relação entre o tamanho das cidades e o tamanho do buffer utilizado nesses trabalhos, optou-se por buffer de $1 \mathrm{~km}$.

Para a modelagem utilizou-se dados de 1000 pontos randômicos dentro dos buffers. Essa redução na amostragem foi necessária devido a complexidade do cálculo da GWR, que exige elevada memória e processamento computacional.

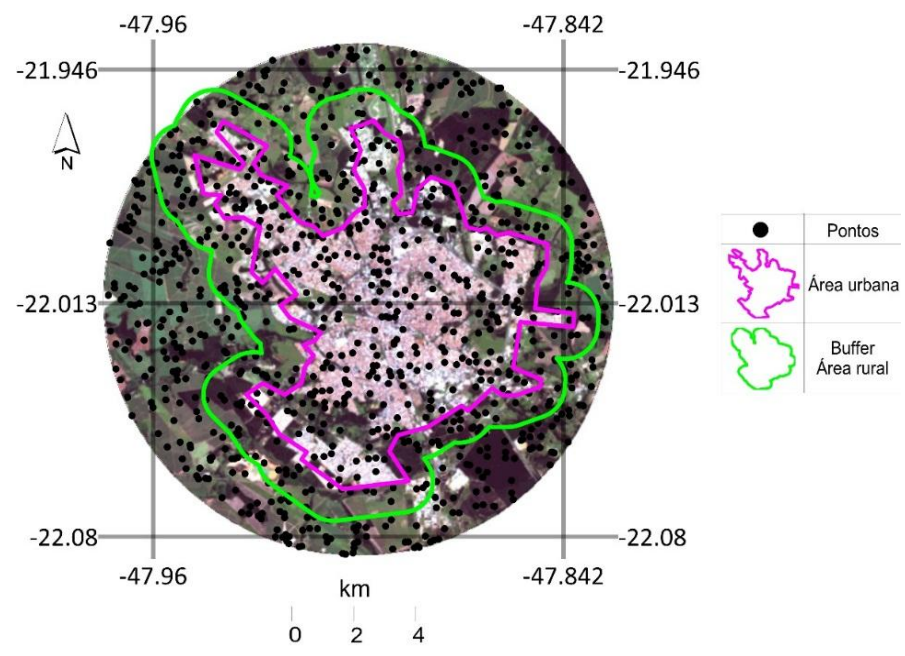


Figura 3 - Pontos randômicos de mensuração dentro do limite urbano e buffer rural da cidade de São Carlos.

\subsection{VARIÁVEIS INDEPENDENTES}

As variáveis independentes: altitude e índice de posição topográfica, foram calculadas a partir dos dados SRTM. Enquanto que as variáveis IU, NDVI e NDWI foram obtidas por meio das imagens do satélite LANDSAT 8.

\subsubsection{ALTITUDE}

A altitude ou a altura acima do nível médio do mar é um fator chave que controla a temperatura do ar. Áreas com diferentes altitudes podem acarretar variação na temperatura do ar e na emissividade atmosférica, o que poderá causar variações na temperatura da superfície (LI et al., 2010).

Utilizou-se dos dados do projeto TOPODATA que oferece livre acesso a variáveis geomorfométricas, derivadas de dados SRTM (Shuttle Radar Topographic Mission) para todo o território brasileiro. Esses dados foram refinados da resolução espacial original de 3 arco-segundos ( $\sim 90 \mathrm{~m}$ ) para 1 arco-segundo ( $30 \mathrm{~m})$ por krigagem.

\subsection{2 ÍNDICE DE POSIÇÃO TOPOGRÁFICA (IPT)}

O Índice de Posição Topográfica (IPT), é um algoritmo criado por Weiss em 2001 (TRENTIN; ROBAINA; BARATTO, 2016), que calcula a diferença da elevação entre um pixel central $(Z 0)$ e a média da elevação do seu entorno $(\mathrm{Zm})$, o valor do IPT expressa a intensidade do contraste (IVAJNŠIČ; KALIGARIČ; ŽIBERNA, 2014; TRENTIN; ROBAINA; BARATTO, 2016).

$O$ Índice de Posição Topográfico é um índice que possibilita a determinação de características da paisagem levando em consideração os atributos topográficos da área de estudo, desta forma, as unidades definidas apresentam uma estreita relação com condições de escoamentos hídrico e de dinâmica superficial (TRENTIN; ROBAINA; BARATTO, 2016).

O IPT é a diferença entre um valor de elevação de células e a altitude média da vizinhança em torno dessas células. Valores positivos significam que a célula é mais elevada do que os seus arredores, enquanto valores negativos significam que é mais baixa. Se ele é significativamente mais elevado do que a zona circundante, então é provável que esteja perto ou no topo de uma colina ou cume. Os valores significativamente baixos sugerem que a célula está perto ou no fundo de um vale (TRENTIN; ROBAINA; BARATTO, 2016). O IPT com valores próximos de zero pode significar, tanto uma área plana, ou uma área de inclinação média.

A variação na inclinação e orientação das vertentes do relevo desempenha, associada à variação da altitude, importante papel na distribuição da energia calorífico-luminosa (LI et al., 2010; PASZYNSKI, 1991). O fluxo radiativo de uma vertente inclinada poderá ser bem mais intenso que de outra, em determinado período do dia, entretanto, em outros períodos a incidência dos raios solares pode ser significativamente menor. Da mesma forma, o sombreamento de edifícios e árvores, dentre outros, será mais expressivo em áreas planas (IVAJNŠIČ; KALIGARIČ; ŽIBERNA, 2014; LI et al., 2010). 


\subsection{3 ÍNDICE DE URBANIZAÇÃO (IU)}

O Índice de Urbanização (equação 2) foi calculado usando as bandas 5 e 7 do satélite LANDSAT 8, este índice foi proposto pelos autores Kawamura; Jayamanna e Tsujiko (1996) para estimar a urbanização, podendo variar de -1 a 1: quanto maior o valor, maior é o grau de urbanização.

$I U=\frac{\rho_{7}-\rho_{5}}{\rho_{7}+\rho_{5}} \times 100$

Onde $I U$ é o indice de Urbanização. $\rho_{7}$ é a reflectância da banda 7 e $\rho_{5}$ a reflectância da banda 5 do satélite LANDSAT 8.

\subsubsection{NORMALIZED DIFFERENCE VEGETATION INDEX (NDVI)}

O NDVI foi obtido pela razão entre a diferença da medida da refletância nos canais do infravermelho próximo $\left(\rho_{5}\right)$ e vermelho $\left(\rho_{4}\right)$ e a soma desses canais (equação 3 ).

$N D V I=\frac{\rho_{5}-\rho_{4}}{\rho_{5}+\rho_{4}}$

O NDVI é um indicador da quantidade e da condição da vegetação verde. Os valores variam de -1 a +1 , valores positivos são obtidos em áreas com algum tipo de vegetação, e varia de acordo com a atividade fotossintética das plantas nessa área e sua densidade, enquanto que superfícies com água o NDVI, geralmente, é menor que zero (ALVES, 2016a; FOODY, 2003; FOTHERINGHAM; BRUNSDON; CHARLTON, 2002).

\subsection{5 ÍNDICE DA DIFERENÇA NORMALIZADA DE ÁGUA (NDWI)}

O Índice da Diferença Normalizada de Água (Normalized Difference Water Index - NDWI), foi desenvolvido por McFeeters em 1996, o intuito do autor era delinear feições presentes no ambiente aquático, e realçar sua presença nas imagens (PEREIRA; LOHMANN; MAGANHOTTO, 2016). A água tem importância no balanço térmico, devido a sua capacidade de absorver energia e de liberá-la lentamente. O NDWI pode ser definido conforme equação 4.

$\mathrm{NDWI}=\frac{\rho_{3}-\rho_{5}}{\rho_{3}+\rho_{5}}$

O valor de NDWI varia de -1 a 1 . O valor zero é um limiar, ou seja, o tipo de cobertura é considerado água se NDWI $\geq 0$ e não água se NDWI $\leq 0$.

\subsection{MODELOS}

Os modelos GWR e MQO utilizaram as variáveis independentes: altitude; TPI; IU, NDVI e NDWI, para modelar a ICUS. 


\subsubsection{MODELO DOS MÍNIMOS QUADRADOS ORDINÁRIOS (MQO)}

Mínimos Quadrados Ordinários (MQO) é um modelo não espacial (equação 5), isto é, nenhuma informação de localização geográfica é considerada na estimativa dos parâmetros do modelo, e todos os parâmetros são médias em relação a todo o conjunto de dados, ou seja, é um modelo que representa o padrão global do fenômeno estudado. O MQO convencional pode ser expresso como (FOTHERINGHAM; BRUNSDON; CHARLTON, 2002):

$y_{i}=\beta_{0}+\sum_{k} \beta_{k} x_{i k}+\varepsilon_{i}$

Em que $y_{i}, x_{i k}$ e $\varepsilon_{i}$ representam as variáveis dependentes, a variável dependente e o erro aleatório de diferentes pontos espaciais (os subitens $i$ e $k$ representam as localizações espaciais e o número da variável dependente, respectivamente). $\beta_{0}$ é o intercepto do modelo $\beta_{k}$ é o coeficiente de inclinação para as variáveis independentes $x_{k}$.

\subsubsection{MODELO DA REGRESSÃO GEOGRAFICAMENTE PONDERADA (GWR)}

A técnica de Regressão Geograficamente Ponderada, em inglês Geographically Weighted Regression (GWR) (FOTHERINGHAM; BRUNSDON; CHARLTON, 2002), é utilizada para modelar processos heterogêneos (não estacionários) espacialmente, isto é, processos que variam (seja na média, mediana, variância etc.) de região para região. A ideia básica da GWR é ajustar um modelo de regressão para cada região do conjunto de dados utilizando a localização geográfica das demais observações para ponderar as estimativas dos parâmetros (FOTHERINGHAM; BRUNSDON; CHARLTON, 2002).

A aplicação do modelo GWR pode ser observada em diferentes linhas de investigação: Brown et al., (2012) usaram o modelo GWR para examinar a relação entre a cobertura da superfície, chuvas e habitat de águas superficiais em 149 sub-bacias em uma região predominantemente de agricultura cobrindo 2,6 milhões de hectares no sudeste da Austrália. Kang et al., (2014) usaram o modelo GWR para explorar os padrões espaciais e fatores locais na correlação NDVI - precipitação. Wu et al., (2016) objetivaram explorar a viabilidade de GWR na predição da salinidade do solo porque, segundo os autores, os métodos de predição da salinidade do solo no delta do rio Yellow ainda são de baixa precisão. Kumari et al., (2016) quantificaram a intensidade da relação entre a variabilidade espacial e a topografia do Himalaia Central. Oliveira et al., (2014) exploraram os padrões espaciais da densidade do fogo na Europa meridional usando GWR.

Muitos fenômenos ambientais possuem relação com o espaço e não estão distribuídos aleatoriamente no espaço, como pressuposto dos modelos globais (o MQO). Desta forma, a aplicação de modelos tradicionais, sem a incorporação de atributos geográficos, pode conduzir à superestimação da significância dos parâmetros dos modelos, além de evidenciar associações espúrias (ZHAO et al., 2015). Para evitar problemas dessa natureza na modelagem da ICUS, a incorporação do caráter espacial na calibração de modelos de regressão linear 
pode ser efetuada por meio da técnica de ponderação geográfica (FOTHERINGHAM; BRUNSDON; CHARLTON, 2002). Cabe destacar que a modelagem geograficamente ponderada tem necessariamente um efeito local, na medida em que assume a hipótese de não estacionariedade espacial da variável dependente. Seu grande diferencial em termos de poder explicativo é produzir, em vez de uma única relação de dependência válida para toda a área de estudo (modelo global), relações específicas para cada região (modelos locais) em que ocorrem influências locais motivadas pela autocorrelação espacial do fenômeno analisado.

O modelo GWR estende o modelo global convencional da equação 8, adicionando um parâmetro de localização geográfica (FOTHERINGHAM; BRUNSDON; CHARLTON, 2002), podendo ser reescrito como (equação 6):

$y_{i}=\beta_{0}\left(u_{i}, v_{i}\right)+\sum_{k} \beta_{k}\left(u_{i}, v_{i}\right) x_{i k}+\varepsilon_{i}$

Na qual a variável dependente $y$ é regredida em um conjunto de variáveis independentes, cada uma denotada por $x_{k}$ com os parâmetros variando sobre o espaço, $\left(u_{i}, v_{i}\right)$ denota as coordenadas de longitude e latitude do enésimo ponto no espaço e $\beta_{k}\left(u_{i}, v_{i}\right)$ é o coeficiente local no ponto $i$ (FOTHERINGHAM; BRUNSDON; CHARLTON, 2002).

\subsubsection{CRITÉRIO DE INFORMAÇÃO AKAIKE (AIC)}

O modelo GWR produz informações que explicam a variação espacial a partir das associações entre variáveis. A hipótese é que as características adjacentes têm um efeito maior nas estimativas dos parâmetros que as características mais distantes espacialmente (AL-AHMADI; AL-AHMADI, 2013; MENNIS, 2006). Para especificar a estrutura de ponderação geográfica o modelo GWR requer a especificação de uma forma de kernel e uma largura de banda. Em geral, se as observações são regularmente distribuídas na área de estudo, então um kernel com uma largura de banda fixa é uma escolha apropriada. Se as observações são agrupadas e não são regularmente espaçadas, o kernel com uma largura de banda adaptável deve ser utilizado (FOTHERINGHAM; BRUNSDON; CHARLTON, 2002),. A largura de banda pode ser atribuída por meio de três métodos: 1- pelo usuário de forma arbitrária; pela função de validação cruzada e pelo critério de informação Akaike (AIC). A qualidade de ajuste que tem sido usada amplamente no modelo GWR é o AIC corrigido (AICC) (FOTHERINGHAM; BRUNSDON; CHARLTON, 2002), portanto, o AICc será usado nesta pesquisa (equação 7):

$A I C c=2 n \log _{e}(\bar{\sigma})+n \log _{e}(2 \pi)+n\left\{\frac{n+\operatorname{tr}(S)}{n-2-\operatorname{tr}(S)}\right\}$

Em que $n$ é o número de observações do conjunto de dados, $\bar{\sigma}$ é a estimativa do desvio padrão dos resíduos e $\operatorname{tr}(S)$ é o traço da matriz (FOTHERINGHAM; BRUNSDON; CHARLTON, 2002). Um valor mais baixo de AIC indica que o modelo está mais próximo da realidade. 


\subsection{4 ÍNDICE MORAN}

Regressão residual é a diferença entre os valores observados e previstos. Presume-se que seja distribuído aleatoriamente em modelos globais (MOQ) e locais (GWR). Resíduos com maior autocorrelação espacial indicam que o modelo de regressão é insuficiente ou tendencioso. Em contraste, a autocorrelação espacial mais baixa entre os resíduos indica a melhor regressão na qual a correlação é modelada adequadamente (FOTHERINGHAM; BRUNSDON; CHARLTON, 2002; KANG et al., 2014). Nesse trabalho, a autocorrelação espacial global entre todos os resíduos de regressão foi analisada por meio do índice Moran (IM). O índice estatístico de Moran para a autocorrelação espacial é dado como (equação 8):

$I M=\frac{n}{S_{O}} \frac{\sum_{i=1}^{n} \sum_{j=1}^{n} \omega_{i, j} Z_{i} Z_{j}}{\sum_{i=1}^{n} Z_{i}^{2}}$

Em que $Z_{i}$ e $Z_{j}$ são os desvios em relação a média $\left(Z_{i}-\bar{Z}\right), \omega_{i, j}$ é o elemento na matriz de vizinhança para o par $i$ e $j, n$ é o número total de observações, finalmente, $S_{O}$ é a soma dos pesos espaciais. De forma geral, o Índice Moran presta-se a um teste cuja hipótese nula é de independência espacial, neste caso, seu valor seria zero. Valores positivos (entre 0 e 1) indicam correlação direta e negativos (entre -1 e 0) correlação inversa.

Neste estudo, os modelos GWR e MQO foram analisados usando o programa SAM ${ }^{\circledR} 4.0$ (RANGEL; DINIZ-FILHO; BINI, 2010) e todos os mapas foram elaborados no programa Golden Software Surfer ${ }^{\circledR} 14$.

\section{RESULTADOS E DISCUSSÃO}

\subsection{MODELAGEM DA ICUS UTILIZANDO OS MODELOS GWR E MQO}

O fator de inflação de variância (VIF) mede a redundância entre as variáveis explicativas (IVAJNŠIČ; KALIGARIČ; ŽIBERNA, 2014; LI et al., 2010; OLIVEIRA et al., 2014). Como regra geral, as variáveis explicativas com valores de VIF maiores que 7,5 devem ser removidas do modelo de regressão. Em todas estações do ano a variável NDWI teve que ser retirada e a variável IU foi retirada apenas no modelo estabelecido para o verão, ambas por apresentarem valor de VIF acima do indicado, as outras variáveis obtiveram VIF abaixo de 7,5 (Tabela 2). Todos os coeficientes do modelo MQO, exceto o TPI, foram estatisticamente significativos $(p$-value $<0,05)$. Por isso, o TPI não foi utilizado. Essa etapa inicial foi importante para otimizar o modelo MQO, estabelecendo as variáveis que contribuirão significativamente para explicar a variabilidade da ICUS. 
Tabela 2 - Características sazonais do modelo de regressão global (MQO).

\begin{tabular}{cccccccc}
\hline \multirow{4}{*}{ Coeff. } & Estações & Constant & Altitude & IU & NDVI & NDWI & TPI \\
& Verão & 11.384 & -0.006 & - & -10.431 & - & 0.02 \\
& Outono & 4.496 & -0.001 & 0.005 & -4.876 & - & -0.002 \\
& Inverno & 9.523 & -0.007 & -0.021 & -9.924 & - & 0.036 \\
& Primavera & 8.101 & -0.005 & -0.024 & -11.883 & - & $<.001$ \\
\hline \multirow{4}{*}{ VIF } & Verão & 0 & 1.009 & - & 1.004 & - & 1.009 \\
& Outono & 0 & 1.091 & 2.51 & 2.597 & - & 1.009 \\
& Inverno & 0 & 1.025 & 1.932 & 1.951 & - & 1.009 \\
& Primavera & 0 & 1.039 & 1.811 & 1.849 & - & 1.01 \\
\hline \multirow{4}{*}{$p$-value } & Verão & $<.001$ & $<.001$ & - & $<.001$ & - & 0.653 \\
& Outono & $<.001$ & 0.001 & $<.001$ & $<.001$ & - & 0.928 \\
& Inverno & $<.001$ & $<.001$ & $<.001$ & $<.001$ & - & 0.453 \\
& Primavera & $<.001$ & $<.001$ & 0 & $<.001$ & - & 0.995 \\
\hline
\end{tabular}

\subsubsection{AUTOCORRELAÇÃO ESPACIAL DOS RESÍDUOS}

O método de autocorrelação espacial, índice Moran (IM), pode ser usado para examinar se os resíduos do modelo GWR e MQO exibem ou não agregação espacial estatisticamente significativa. A autocorrelação é uma expressão da falta de independência entre pares de observações a distâncias estabelecidas, no tempo e no espaço (ZHAO et al., 2015).

Geralmente, a alta aleatoriedade dos resíduos simulados e a quantidade residual cumulativa indicaram melhor desempenho do modelo de regressão. A distribuição espacial dos resíduos simulados dos modelos GWR e MQO é mostrada na figura 4. O índice Moran dos resíduos do modelo GWR apresentou relações mais confiáveis em todas as estações do ano, reduzindo as autocorrelações espaciais dos resíduos (IM próximo a zero), enquanto que o modelo MQO obteve IM acima 0,2 sugerindo menor aleatoriedade dos padrões espaciais dos resíduos.

A comparação da autocorrelação dos resíduos dos modelos GWR e MQO, em diferentes campos de pesquisa, tem mostrado que o GWR minimiza a autocorreção dos resíduos, melhorando o modelo preditivo: (GAO et al., 2012) ao investigarem a relação entre o NDVI e fatores ambientais; (SZYMANOWSKI; KRYZA, 2012) ao analisarem modelos de regressão para ilha de calor urbana; (CHU, 2012) ao avaliar a relação entre a altitude e os extremos de precipitação em vários períodos de duração; (WANG et al., 2016) quando analisaram os fatores explicativos das inundações pluviais urbanas; (ACHARYA et al., 2018) ao modelar os fatores de risco da dengue. Embora (WANG; LEE; WILLIAMS, 2019) não tenham observado a necessidade de se utilizar o modelo GWR na análise dos padrões espaciais e sociais dos crimes violentos em Toronto. 

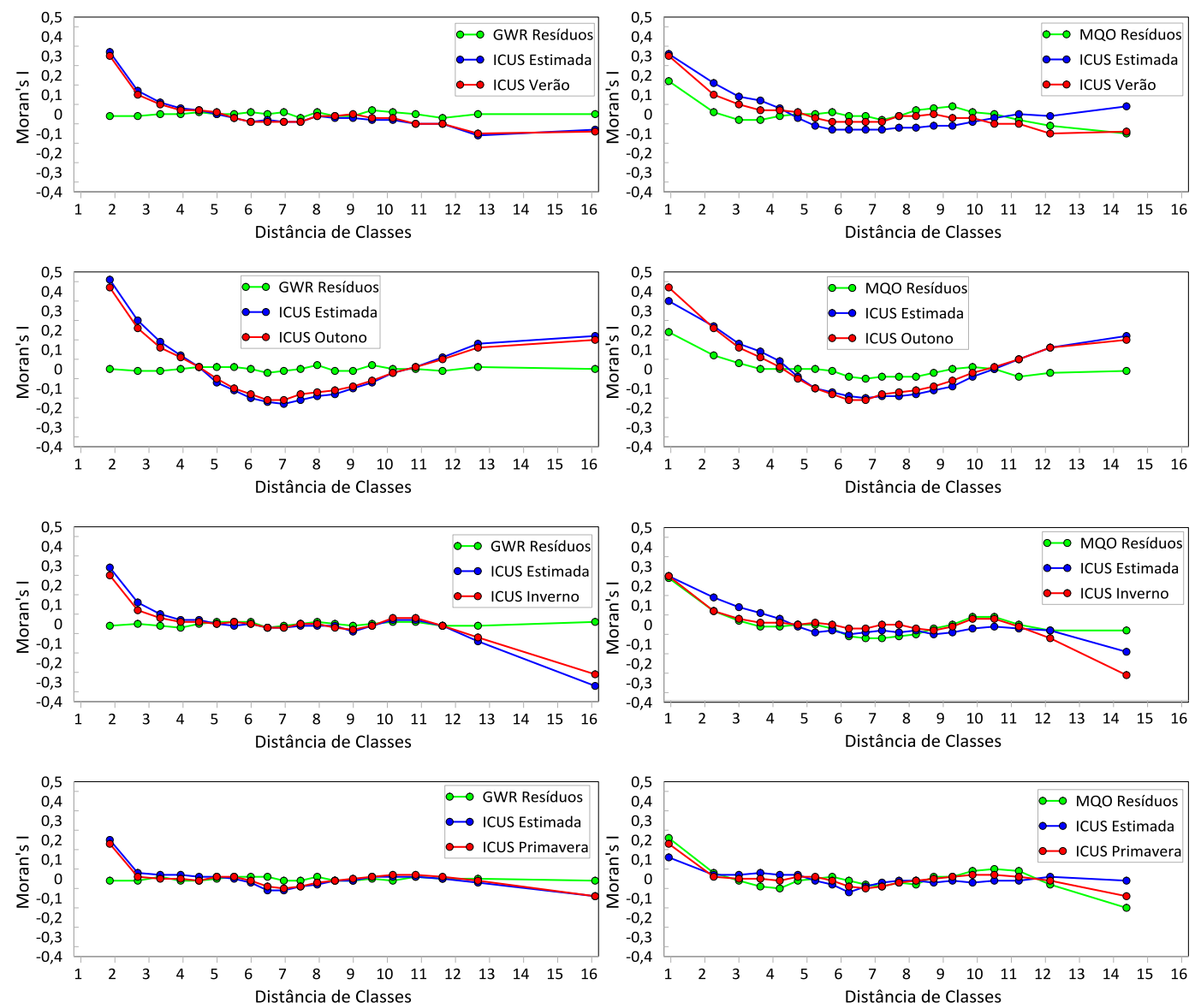

Figura 4 - Variabilidade do índice Moran da ICUS estimada, observada e nos resíduos dos modelos GWR e MQO.

\subsubsection{COMPARAÇÃO SAZONAL DOS MODELOS GWR E MQO}

Uma série de testes foi realizada para comparar o desempenho dos modelos GWR e MQO (Tabela 3). A comparação foi realizada analisando os valores de $r^{2}$ e AICc dos modelos. Além de usar o AICc para calcular uma distância de largura de banda ideal, o software SAM 4.0 calcula outro valor AICc que é usado para comparações entre diferentes modelos. Valores de $r^{2}$ mais elevados indicam maior capacidade do modelo de explicar mais variações da variável dependente como função das variáveis independentes. O AICc é um indicador da precisão e da complexidade do modelo, as diminuições no valor do AICc indicam que o modelo está mais próximo da realidade (AL-AHMADI; ALAHMADI, 2013; BROWN et al., 2012; FOTHERINGHAM; BRUNSDON; CHARLTON, 2002; MENNIS, 2006).

Os parâmetros de diagnóstico mostram as diferenças de desempenho entre os modelos GWR e MQO (Tabela 3). Em todas as estações do ano os valores do $r^{2}$ do modelo GWR foram superiores ao modelo MQO: no inverno o valor de $r^{2}$ foi de 0,81 e 0,57 para os modelos GWR e MQO, respectivamente. O modelo GWR explicou $81 \%$ da variância da intensidade das ICUS, que foi $24 \%$ maior que o desempenho do modelo MQO, que explicou $57 \%$ da variância, essa 
foi a maior variação do $r^{2}$ entre os modelos. Em termos de $r^{2}$ ajustado, $o$ modelo GWR, com um valor de 0,78 , também foi maior que modelo MQO, cujo valor foi de 0,56, ou seja, variação de $22 \%$. Em contraste, o valor AICc do modelo GWR para o inverno foi de 2835, que foi inferior ao do modelo MQO com 3361; na primavera foi observada a segunda maior variação do $r^{2}, r^{2}$ ajustado e AICc do modelo GWR com o MQO, com variação de $22 \%$ no $r^{2}$ e $19 \%$ no $r^{2}$ ajustado, e diferença de -467 ; nas estações de outono e verão a variação foi menor, entretanto, significativa.

O $\mathrm{r}^{2}$ do modelo GWR variou de 0,81 (inverno e primavera) a 0,9 (verão) enquanto no modelo MQO a variação foi de 0,57 (inverno) a 0,79 (verão). Além disso, o índice Moran dos resíduos para o modelo MQO foram relativamente elevados indicando que eles são significativamente autocorrelacionados espacialmente $(p<0,05)$. Em contraste, o índice Moran para o modelo GWR foi baixo, próximo a zero, indicando que autocorrelações espaciais extremamente fracas ou inexistentes (Figura 4). Tanto os valores de $r^{2}$ e AICc, quanto as autocorrelações espaciais muito fracas dos resíduos estimados, demonstraram que o modelo GWR teve um desempenho muito superior ao modelo MQO. O GWR reduziu os erros das estimações individuais e suas autocorrelações espaciais, em comparação com o modelo MQO. Entretanto, ressalta-se que o $p$ value foi significativo em todos os casos para ambos os modelos.

Tabela 3 - Comparação estatística dos modelos GWR e MQO.

\begin{tabular}{ccccccccc}
\hline \multirow{2}{*}{ Estatíticas } & \multicolumn{2}{c}{ Verão } & \multicolumn{2}{c}{ Outono } & \multicolumn{2}{c}{ Inverno } & \multicolumn{2}{c}{ Primavera } \\
\cline { 2 - 9 } & GWR & MQO & GWR & MQO & GWR & MQO & GWR & MQO \\
\hline Akaike Information Criterion & 2648 & 3092 & 1597 & 2053 & 2835 & 3361 & 2941 & 3408 \\
(AICc) & 0,95 & 0,89 & 0,93 & 0,84 & 0,9 & 0,75 & 0,9 & 0,77 \\
$\begin{array}{c}\text { Coeficiente de correlação } \\
\text { Coeficiente de determinação }\left(r^{2}\right)\end{array}$ & 0,9 & 0,79 & 0,86 & 0,71 & 0,81 & 0,57 & 0,81 & 0,59 \\
$\begin{array}{c}\text { Coeficiente de determinação } \\
\text { ajustado }\left(r^{2}\right)\end{array}$ & 0,88 & 0,79 & 0,84 & 0,71 & 0,78 & 0,56 & 0,78 & 0,59 \\
F $\left(r^{2}\right):$ & 59 & 752 & 41 & 485 & 28 & 259 & 28 & 289 \\
p-value $\left(r^{2}\right):$ & 0 & $<0,0$ & 0 & 0 & 0 & 0 & 01 & 01 \\
\hline
\end{tabular}

Nesse estudo, os resíduos dos modelos de regressão são as discrepâncias entre os valores de ICUS observados e os valores de ICUS estimados, quanto maior o resíduo maior é a discrepância. Resíduos positivos indicam que o modelo subestima a ICUS e resíduos negativos indicam superestimação. A variabilidade espacial e sazonal dos resíduos do modelo GWR e MQO pode ser observada na figura 5 . Nota-se que os resíduos denotam tanto superestimação como subestimação, em todas as estações o modelo GWR gerou resíduos menores que os do modelo MQO. Embora no outono os resíduos, em ambos os modelos, apresentaram padrões e intensidades ligeiramente semelhantes, no verão, inverno e primavera o modelo MQO gerou resíduos elevados $\left(-3,7{ }^{\circ} \mathrm{C}\right.$ e $4,4^{\circ} \mathrm{C}$ ) enquanto os resíduos do GWR ficaram próximos de zero, com $2,5^{\circ} \mathrm{C}$ em locais aleatórios. 


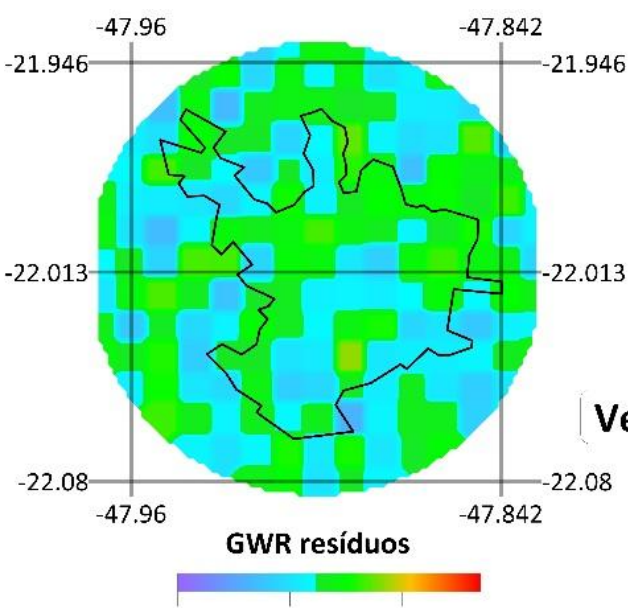

$\begin{array}{llllll}-3.7 & -2.2 & -0.7 & 0.8 & 2.3 & 3.8\end{array}$

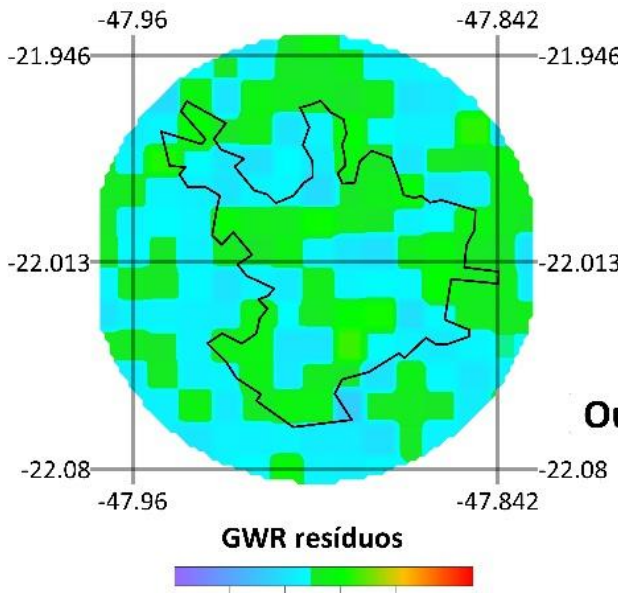

$\begin{array}{llllll}-3.7 & -2.2 & -0.7 & 0.8 & 2.3 & 3.8\end{array}$

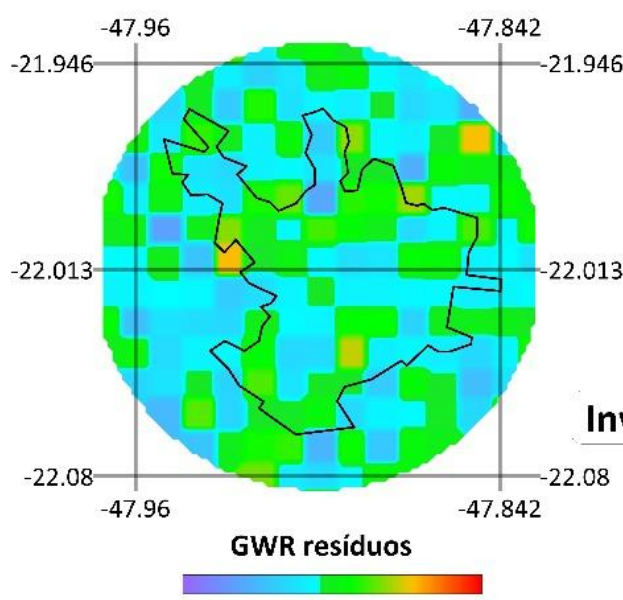

$\begin{array}{llllll}-3.7 & -2.2 & -0.7 & 0.8 & 2.3 & 3.8\end{array}$

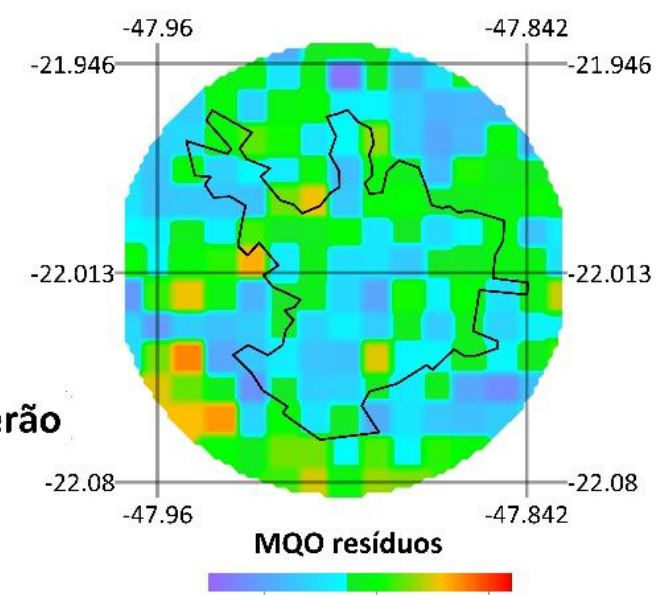

$\begin{array}{llllll}-3.7 & -2.2 & -0.7 & 0.8 & 2.3 & 3.8\end{array}$

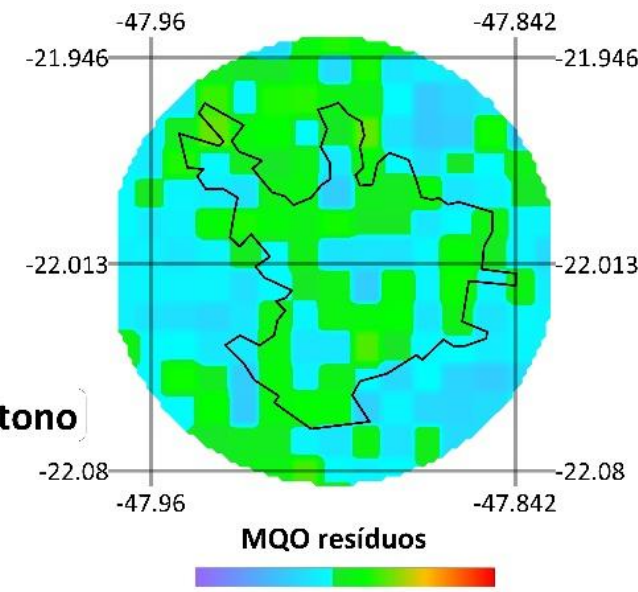

$\begin{array}{lllllll}-3.7 & -2.2 & -0.7 & 0.8 & 2.3 & 3.8\end{array}$

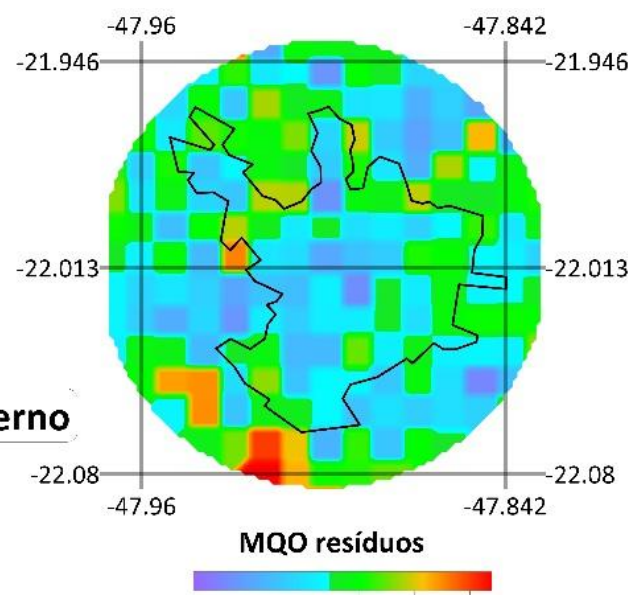

$\begin{array}{llllll}-3.7 & -2.2 & -0.7 & 0.8 & 2.3 & 3.8\end{array}$ 


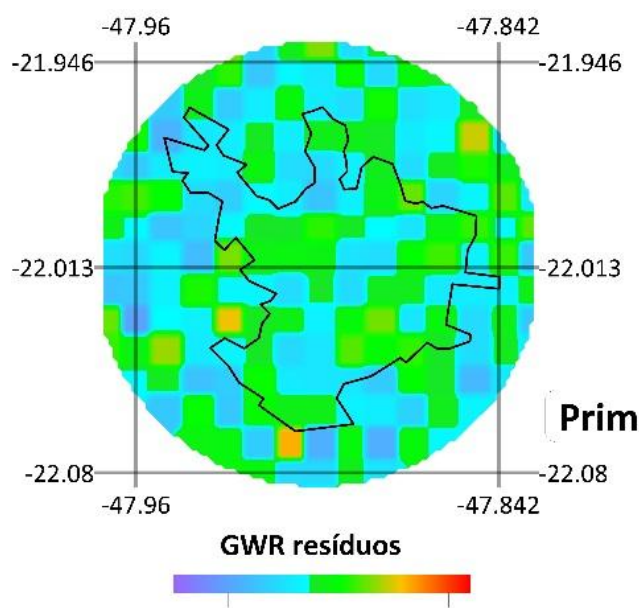

$\begin{array}{llllll}-3.7 & -2.2 & -0.7 & 0.8 & 2.3 & 3.8\end{array}$

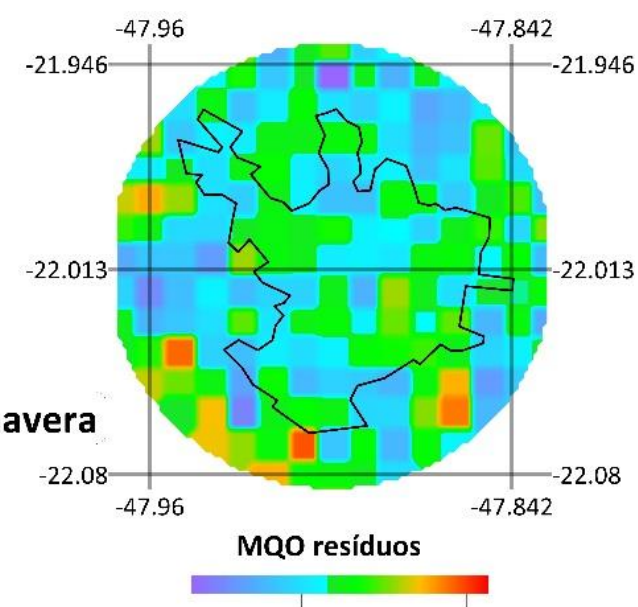

$\begin{array}{llllll}-3.7 & -2.2 & -0.7 & 0.8 & 2.3 & 3.8\end{array}$

Figura 5 - Resíduos dos modelos GWR e MQO da ICUS no verão, outono, inverno e primavera.

\subsubsection{CARACTERÍSTICAS DA MODELAGEM DA ICUS USANDO O MODELO GWR}

\subsubsection{COEFICIENTE LOCAL DE DETERMINAÇÃO $\left(R^{2}\right)$}

Os coeficientes de determinação da tabela 2 referem-se à capacidade dos modelos GWR e MQO em explicar a variabilidade da ICUS, enquanto que a figura 5 mostra a frequência dos coeficientes locais de determinação em classes e a figura 6 o conjunto dos $r^{2}$ locais do modelo GWR. O maior número de $r^{2}$ locais acima de 0,8 foi notabilizado no verão, enquanto que o maior conjunto de dados com $r^{2}$ abaixo de 0,6 foi observado no inverno, essas variações locais refletiram no $r^{2}$ geral do modelo GWR, conforme tabela 2 . Contudo, observa-se que as maiores frequências (Figura 6) e o maior conjunto de observações (Figura 7) dos coeficientes de determinação foram com valores elevados. Essas variações dos $r^{2}$ locais denotam a característica espacial intrínseca do fenômeno ICUS, assim como a variabilidade sazonal oriunda, neste caso, principalmente do NDVI e NDWI que possuem variação interanual significativa, devido a distribuição pluviométrica em São Carlos. 

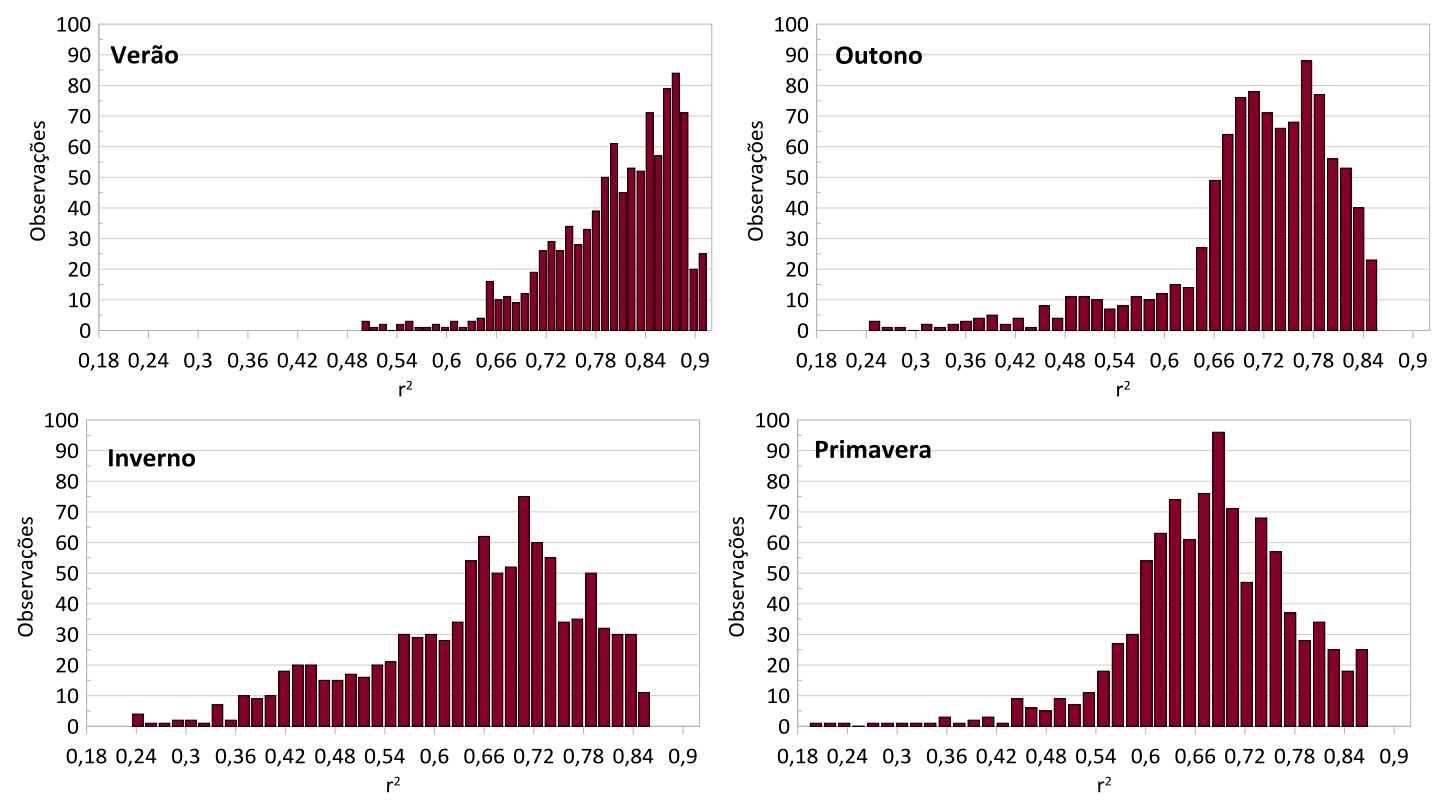

Figura 6 - Histogramas dos coeficientes locais de determinação do modelo GWR.

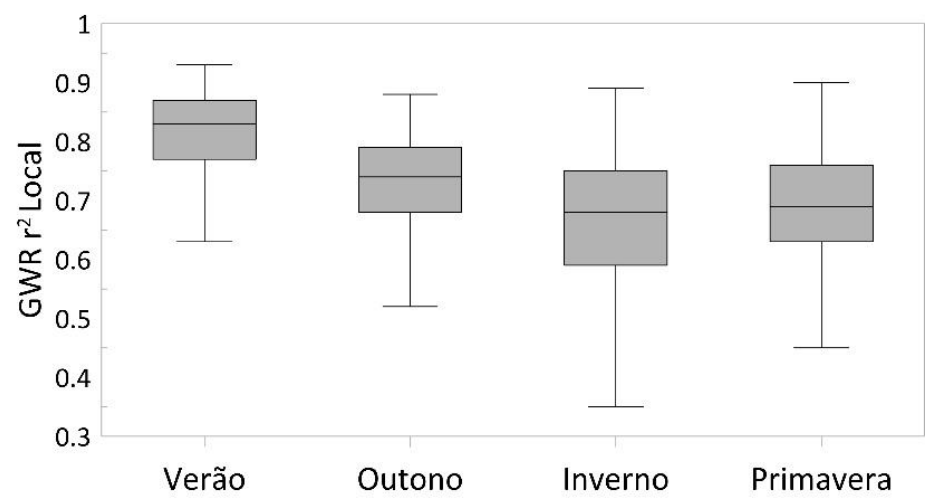

Figura 7 - Bloxplot dos coeficientes locais de determinação do modelo GWR.

\section{CONCLUSÃO}

Nesse estudo, uma regressão global (MQO) e uma geograficamente ponderada (GWR) foram utilizadas para investigar as variações sazonais das associações espaciais não estacionárias entre a ilha de calor urbana de superfície (ICUS) e variáveis naturais e antrópicas, assim estratégias locais para a dimuição da intensidade das ICUS podem ser formuladas para melhorar a qualidade de vida na área urbana de São Carlos.

As associações entre a ICUS e todos as 5 variáveis independentes (Altitude, IU, NDVI, NDWI e TPI) apresentam variações sazonais significativas, relações lineares foram observadas para as variáveis NDVI, NDWI e IU, entretanto, a variável NDWI não foi utilizada no modelo MQO porque apresentou VIF maior que 7,5 denotando autocorrelação com as variáveis independentes e o IU não foi utilizado no verão pelo mesmo motivo. 
O modelo MQO gerou coeficientes de terminação $\left(r^{2}\right)$ inferiores e resíduos superiores ao modelo GWR, enquanto que o índice Moran do GWR ficou próximo de zero, sugerindo baixa autocorrelação espacial dos resíduos e melhor desempenho.

Existem várias limitações que merecem ser discutidas. Em primeiro lugar, esse estudo não incluiu nas modelos variáveis relacionadas às funções urbanas devido à falta de dados. O clima urbano é um produto integrado da complexa interatividade da forma urbana e da função urbana com a atmosfera suprajacente. Por isso, é importante, também, abranger a função urbana, como a emissão de calor industrial e antropogênico na modelagem.

Em terceiro lugar, apesar da frequência constante de amostragem de dados dos sensores de satélite, no caso o Landsat 8 , os períodos em que há grande nebulosidade impedem uma análise espaço-temporal do ambiente térmico urbano mais aprofundada, além disso o satélite Landsat 8 passa na área de estudo, normalmente, às $10 \mathrm{~h}$ da manhã, impossibilitando análise intra-diária.

A influência da escala regional na escala local - cidade de São Carlos, também não é explicitamente explorada. Em futuros estudos, tanto a forma urbana como a função urbana serão integradas na modelagem. Além disso, indicadores mais detalhados sobre vegetação e estrutura de blocos do modelo GWR são necessários para se descobrir o mecanismo subjacente da associação espacial não-estacionária com a ICUS.

Contudo, a relação ICUS com a paisagem urbana possui grande variabilidade sazonal, portanto, é crucial que a mitigação da ICUS e a modelagem climática considerem tais efeitos sazonais. Geralmente, esse efeito sazonal é gerado através da variação sazonal da radiação solar e das propriedades biogeofísicas da paisagem. Por exemplo, árvores perenes são capazes de reduzir a exposição ao ar frio e ao vento, enquanto as árvores decíduas são incapazes de fazê-lo, em contrapartida, as árvores perenes, interceptam a radiação solar e impedem que ela chegue na superfície, diminuindo a temperatura de superfície e consequentemente a ICUS. Por isso, é importante que os planejadores urbanos considerem esse efeito sazonal para que que a política de arborização seja eficaz. No Brasil não existe estudo sobre a ICUS utilizando o modelo GWR, portanto, essa pesquisa poderá servir como pressuposto metodológico a ser aplicado em outras cidades brasileiras.

\section{AGRADECIMENTOS}

Agradeço ao IF Goiano - Campus Ceres pela concessão da Liberação e afastamento para realização da pesquisa de Pós-Doutorado no Departamento de Geografia da Faculdade de Filosofia, Letras e Ciências Humanas da Universidade de São Paulo.

\section{REFERÊNCIAS}

ABREU-HARBICH, L. V.; LABAKI, L. C.; MATZARAKIS, A. Thermal bioclimate in idealized urban street canyons in Campinas, Brazil. Theoretical and Applied Climatology, 25 abr. 2013.

ACHARYA, B. K. et al. Modeling the spatially varying risk factors of dengue fever in Jhapa district, Nepal, using the semi-parametric geographically weighted 
regression model. International Journal of Biometeorology, v. 62, p. 1973-1986, 2018.

AL-AHMADI, K.; AL-AHMADI, S. Rainfall-Altitude Relationship in Saudi Arabia. Advances in Meteorology, v. 2013, p. 1-14, 2013.

ALCOFORADO, M.-J. et al. A ilha de calor em Lisboa. Aquisição de dados e primeiros resultados estatísticos para aplicação ao ordenamento urbano. In: Geophilia - o sentir e os sentidos da Geografia Homenagem a Jorge Gaspar. [s.I: s.n.]. p. 593-612.

ALCOFORADO, M.-J. et al. Application of climatic guidelines to urban planning. Landscape and Urban Planning, v. 90, n. 1-2, p. 56-65, 2009.

ALI-TOUDERT, F. et al. Outdoor thermal comfort in the old desert city of BeniIsguen, Algeria. Climate Research, v. 28, n. 1993, p. 243-256, 2005.

ALVES, E. Seasonal and Spatial Variation of Surface Urban Heat Island Intensity in a Small Urban Agglomerate in Brazil. Climate, v. 4, n. 4, p. 61, 10 dez. $2016 a$.

ALVES, E.; ANJOS, M.; LOPES, A. Multitemporalidade das anomalias da temperatura de superfície: o caso da cidade de Iporá, Brasil. GOT - Journal of Geography and Spatial Planning, n. 12, p. 5-21, 30 dez. 2017.

ALVES, E. D. L. Influência das variáveis naturais e antrópicas nos padrões da temperatura de superfície: análise por meio de regressão linear múltipla. RA'E GA, v. 38, p. 343-362, 2016b.

ALVES, E. D. L. Quantifying the effect of waterways and green areas on the surface temperature. Acta Scientiarum. Technology, v. 39, n. 1, p. 89-96, 2017.

ALVES, E. D. L.; BIUDES, M. S. Análise da temperatura do ar e da umidade relativa: estudo de microclimas. Interthesis, v. 9, n. 2, p. 139-156, 2012.

ALVES, E. D. L.; BIUDES, M. S. Method for determining the footprint area of air temperature and relative humidity. Acta Scientiarum. Technology, v. 35, n. 2, p. 187-194, 18 abr. 2013.

ALVES, E.; LOPES, A. The Urban Heat Island Effect and the Role of Vegetation to Address the Negative Impacts of Local Climate Changes in a Small Brazilian City. Atmosphere, v. 8, n. 2, p. 18, 9 fev. 2017.

AMORIM, M. C. DE C. T.; CARDOSO, R. DOS S. Modelagem espacial da ilha de calor urbana em Presidente Prudente (SP) - Brasil. Revista Brasileira de Climatologia, v. 16, n. 11, p. 29-45, 2015.

AMORIM, M. C. DE C. T.; DUBREUIL, V.; CARDOSO, R. DOS S. Modelagem espacial da ilha de calor urbana em Presidente Prudente (SP) - Brasil. Revista Brasileira de Climatologia, v. 16, n. 11, p. 29-45, 2015.

AMORIM, M. C. DE C. T.; JUNIOR, J. C. U. Os climas das cidades e as relações Sociedade/Natureza. Revista da ANPEGE, v. 12, n. 19, p. 252-278, 2016. 
BALA, R. et al. A comparative study of land surface temperature with different indices on heterogeneous land cover using Landsat 8 data. The International Archives of the Photogrammetry, Remote Sensing and Spatial Information Sciences. Anais....Dehradun: 2018.

BARBOSA, R. V. R. Estudo do campo térmico urbano de São Carlos (SP): análise da intensidade da ilha de calor urbano em episódio climático de verão. [s.l.] Universidade de São Paulo, 2009.

BARBOSA, R. V. R.; VECCHIA, F. Estudos de ilha de calor urbana por meio de imagens do Landsat 7 ETM + : estudo de caso em São Carlos (SP). Minerva, v. 6, n. 3, p. 273-278, 1996.

BERE, T.; TUNDISI, J. G. Epipsammic diatoms in streams influenced by urban pollution, São Carlos, SP, Brazil. Brazilian journal of biology = Revista brasleira de biologia, v. 70, n. 4, p. 920-30, nov. 2010.

BORTOLUCCI, M. A. P. DE C. E S. Moradias urbanas construídas em São Carlos no período cafeeiro. [s.I.] Universidade de São paulo, 1991.

BROWN, S. et al. Assessment of Spatiotemporal Varying Relationships Between Rainfall, Land Cover and Surface Water Area Using Geographically Weighted Regression. Environmental Modeling \& Assessment, v. 17, n. 3, p. 241-254, 11 jun. 2012.

BRUNSDON, C.; FOTHERINGHAM, A. S.; CHARLTON, M. E. Geographically Weighted Regression: A Method for Exploring Spatial Nonstationarity. Geographical Analysis, v. 28, n. 4, p. 281-298, 3 set. 2010.

CAO, X. et al. Quantifying the cool island intensity of urban parks using ASTER and IKONOS data. Landscape and Urban Planning, v. 96, n. 4, p. 224-231, jun. 2010.

CHEVAL, S.; DUMITRESCU, A. The summer surface urban heat island of Bucharest (Romania) retrieved from MODIS images. Theoretical and Applied Climatology, p. 631-640, 2014.

$\mathrm{CHU}, \mathrm{H} .-\mathrm{J}$. Assessing the relationships between elevation and extreme precipitation with various durations in southern Taiwan using spatial regression models. Hydrological Processes, v. 26, n. 21, p. 3174-3181, 15 out. 2012.

COSEO, P.; LARSEN, L. How factors of land use/land cover, building configuration, and adjacent heat sources and sinks explain Urban Heat Islands in Chicago. Landscape and Urban Planning, v. 125, p. 117-129, 2014.

COUTTS, A. M.; BERINGER, J.; TAPPER, N. J. Characteristics influencing the variability of urban $\mathrm{CO} 2$ fluxes in Melbourne, Australia. Atmospheric Environment, v. 41, n. 1, p. 51-62, jan. 2007.

DEBBAGE, N.; SHEPHERD, J. M. The urban heat island effect and city contiguity. Computers, Environment and Urban Systems, v. 54, p. 181-194, nov. 2015.

DUTILLEUL, P.; LEGENDRE, P. Spatial Heterogeneity against Heteroscedasticity: An Ecological Paradigm versus a Statistical Concept. Oikos, v. 66, n. 1, p. 152, 
jan. 1993.

EMBRAPA. Banco de Dados Climáticos do Brasil. Disponível em: <https://www.cnpm.embrapa.br/projetos/bdclima/balanco/resultados/sp/451/b alanco.html>. Acesso em: 17 jan. 2019.

FOODY, G. M. Geographical weighting as a further refinement to regression modelling: An example focused on the NDVI-rainfall relationship. Remote Sensing of Environment, v. 88, n. 3, p. 283-293, 2003.

FOTHERINGHAM, A. S.; BRUNSDON, C.; CHARLTON, M. Geographically Weighted Regression: The Analysis of Spatially Varying Relationships. [s.l.] Wiley, 2002.

GABRIEL, K. M. A.; ENDLICHER, W. R. Urban and rural mortality rates during heat waves in Berlin and Brandenburg, Germany. Environmental pollution, v. 159, n. 8-9, p. 2044-2050, 2011.

GAO, J. et al. Investigating spatial variation in the relationships between NDVI and environmental factors at multi-scales: a case study of Guizhou Karst Plateau, China. International Journal of Remote Sensing, v. 33, n. 7, p. 21122129, 10 abr. 2012.

GARTLAND, L. Heat Islands: Understanding and Mitigating Heat in Urban Areas. London: Routledge, 2012.

GÉMES, O.; TOBAK, Z.; LEEUWEN, B. VAN. Satellite Based Analysis of Surface Urban Heat Island Intensity. Journal of Environmental Geography, v. 9, n. 1-2, p. 23-30, 1 jan. 2016.

IBGE. Panorama. Disponível em: <https://cidades.ibge.gov.br/brasil/sp/saocarlos/panorama>. Acesso em: 1 fev. 2019.

ISAYA NDOSSI, M.; AVDAN, U. Application of Open Source Coding Technologies in the Production of Land Surface Temperature (LST) Maps from Landsat: A PyQGIS Plugin. Remote Sensing, v. 8, n. 5, p. 1-31, 13 maio 2016.

IVAJNŠIČ, D.; KALIGARIČ, M.; ŽIBERNA, I. Geographically weighted regression of the urban heat island of a small city. Applied Geography, v. 53, p. 341-353, 2014.

KANG, L. et al. Use of Geographically Weighted Regression Model for Exploring Spatial Patterns and Local Factors Behind NDVI-Precipitation Correlation. IEEE Journal of Selected Topics in Applied Earth Observations and Remote Sensing, v. 7, n. 11, p. 4530-4538, nov. 2014.

KAWAMURA, M.; JAYAMANNA, S.; TSUJIKO, Y. Relation Between Social and Environmental Conditions in Colombo, Sri Lanka and the Urban Index Estimated by Satellite Remote Sensing Data. International Archives of Photogrammetry and Remote Sensing, v. XXXI, n. B7, p. 321-326, 1996.

KUMARI, M. et al. Geographically weighted regression based quantification of rainfall-topography relationship and rainfall gradient in Central Himalayas. International Journal of Climatology, n. November, 2016. 
LI, S. et al. Investigating spatial non-stationary and scale-dependent relationships between urban surface temperature and environmental factors using geographically weighted regression. Environmental Modelling and Software, v. 25, n. 12, p. 1789-1800, 2010.

LI, S.; MO, H.; DAI, Y. Spatio-temporal Pattern of Urban Cool Island Intensity and Its Eco-environmental Response in Chang-Zhu-Tan Urban Agglomeration. Communications in Information Science and Management Engineering, v. $1, \mathrm{n}$. 9, p. 1-6, 2011.

LOMBARDO, M. A. Ilhas de Calor nas Metrópoles: o exemplo de São Paulo. São Paulo: HUCITEC, 1985.

LOPES, A. et al. Lisbon Urban Heat Island Updated: New Highlights about the Relationships between Thermal Patterns and Wind Regimes. Advances in Meteorology, v. 2013, p. 1-11, 2013.

LUCENA, A. J. DE. Notas Conceituais e Metodológicas em Clima Urbano e Ilhas de Calor. Revista Continentes, v. 2, n. 2, p. 28-59, 2013.

LUO, X.; PENG, Y. Scale Effects of the Relationships between Urban Heat Islands and Impact Factors Based on a Geographically-Weighted Regression Model. Remote Sensing, v. 8, n. 9, p. 760, 15 set. 2016.

MA, Y.; KUANG, Y.; HUANG, N. Coupling urbanization analyses for studying urban thermal environment and its interplay with biophysical parameters based on TM/ETM+ imagery. International Journal of Applied Earth Observation and Geoinformation, v. 12, n. 2, p. 110-118, 2010.

MENNIS, J. Mapping the Results of Geographically Weighted Regression. The Cartographic Journal, v. 43, n. 2, p. 171-179, 18 jul. 2006.

MIHALAKAKOU, G. et al. Application of Neural Networks to the Simulation of the Heat Island over Athens, Greece, Using Synoptic Types as a Predictor. Journal of Applied Meteorology, v. 41, n. 5, p. 519-527, maio 2002.

MINAKI, C.; AMORIM, M. C. DE C. T. Análise da temperatura e da umidade relativa do ar na primavera-verão em Araçatuba/SP. Revista Brasileira de Climatologia, v. 13, p. 236-247, 8 jun. 2014.

MONTEIRO, C. A. DE F. A Dinâmica climática e as chuvas no Estado de São Paulo: estudo geográfico sob forma de atlas. São Paulo: Instituto de Geografia, 1973.

MONTEIRO, C. A. DE F. Teoria e Clima Urbano. [s.l.] Universidade de São paulo, 1976.

NEVES, G. Z. DE F. et al. Variabilidade e mudanças climáticas: análise da tendência da precipitação na estação climatológica do CRHEA/USP em ItirapinaSP. XII Simpósio Brasileiro de Climatologia Geográfica. Anais...Goiânia: Gráfica UFG, 2016.2 Disponível em: <http://www.abclima.ggf.br/sbcg2016/anais/arquivos/eixo_6/trabalho 34).pdf>

NICHOL, J. E.; J.E, N.; NICHOL, J. E. Visualisation of urban surface 
temperatures derived from satellite images. International Journal of Remote Sensing, v. 19, n. 9, p. 1639-1649, 1998.

OKE. City size and the urban heat island. Atmospheric Environment, v. 7, n. 8, p. 769-779, ago. 1973.

OKE, T. R. Canyon geometry and the nocturnal urban heat island: Comparison of scale model and field observations. Journal of Climatology, v. 1, n. 3, p. 237254, 18 jul. 1981.

OLIVEIRA, S. et al. Exploring the spatial patterns of fire density in Southern Europe using Geographically Weighted Regression. Applied Geography, v. 51, p. 143-157, jul. 2014.

PASZYNSKI, J. Mapping urban topoclimates. Energy and Buildings, v. 16, n. 34, p. 1059-1062, 1991.

PEREIRA, G. H. DE A.; LOHMANN, M.; MAGANHOTTO, R. F. Proposta e avaliação de índices para delimitar e mapear corpos d'água utilizando imagens do satélite LANDSAT 8. Revista Brasileira de Geografia Física, v. 09, n. 06, p. 1956-1968, 2016.

RANGEL, T. F.; DINIZ-FILHO, J. A. F.; BINI, L. M. SAM: a comprehensive application for Spatial Analysis in Macroecology. Ecography, v. 33, n. 1, p. 4650, fev. 2010.

RASUL, A.; BALZTER, H.; SMITH, C. Spatial variation of the daytime Surface Urban Cool Island during the dry season in Erbil, Iraqi Kurdistan, from Landsat 8. Urban Climate, v. 14, p. 176-186, 2015.

SAITOH, T. S.; SHIMADA, T.; HOSHI, H. Modeling and simulation of the Tokyo urban heat island. Atmospheric Environment, v. 30, n. 20, p. 3431-3442, 1996.

SOUCH, C.; GRIMMOND, S. Applied climatology: urban climate. Progress in Physical Geography, v. 30, n. 2, p. 270-279, 1 abr. 2006.

SOUZA, L. C. L. et al. Fator de visão do céu e intensidade de ilhas de calor na escala do pedestre. Ambiente Construído, v. 10, n. 4, p. 155-167, 2010.

STEWART, I. D.; OKE, T. R.; KRAYENHOFF, E. S. Evaluation of the 'local climate zone' scheme using temperature observations and model simulations. International Journal of Climatology, v. 34, n. 4, p. 1062-1080, 18 mar. 2014.

SZYMANOWSKI, M.; KRYZA, M. Local regression models for spatial interpolation of urban heat island-an example from Wrocław, SW Poland. Theoretical and Applied Climatology, v. 108, n. 1-2, p. 53-71, 7 abr. 2012.

TAN, J. et al. The urban heat island and its impact on heat waves and human health in Shanghai. International journal of biometeorology, v. 54, n. 1, p. 75$84,2010$.

TAN, M.; LI, X. Quantifying the effects of settlement size on urban heat islands in fairly uniform geographic areas. Habitat International, v. 49, p. 100-106 2015. 
TARIFA, J. R.; AZEVEDO, T. R. DE. Os climas na cidade de São Paulo: teoria e prática. São Paulo: GEOUSP - Coleção Novos Caminhos 4, 2001.

TOROK, S. J. et al. Urban heat island features of southest Australian Towns. Australian Meterological Magazine, v. 50, p. 1-13, 2001.

TRENTIN, R.; ROBAINA, L. E. DE S.; BARATTO, D. DA S. Análise de elementos do relevo através do Topographic Position Index (TPI) da bacia hidrográfica do arroio Puitã - Oeste do Rio Grande do Sul/Brasil. Revista do Departamento de Geografia, v. 31, p. 14-25, 2016.

UNGER, J.; SAVIĆ, S.; GÁL, T. Modelling of the Annual Mean Urban Heat Island Pattern for Planning of Representative Urban Climate Station Network. Advances in Meteorology, v. 2011, p. 1-9, 2011.

USGS. Earth Explorer. Disponível em: <http://earthexplorer.usgs.gov/>. Acesso em: 1 ago. 2016.

VOOGT, J. A.; OKE, T. R. Thermal remote sensing of urban climates. Remote Sensing of Environment, v. 86, n. 3, p. 370-384, 2003.

WANG, C. et al. Analyzing explanatory factors of urban pluvial floods in Shanghai using geographically weighted regression. Stochastic Environmental Research and Risk Assessment, n. November, 29 mar. 2016.

WANG, L.; LEE, G.; WILLIAMS, I. The Spatial and Social Patterning of Property and Violent Crime in Toronto Neighbourhoods: A Spatial-Quantitative Approach. ISPRS Int. J. Geo-Inf., v. 8, n. 51, 2019.

WU, C.; LIU, G.; HUANG, C. Prediction of soil salinity in the Yellow River Delta using geographically weighted regression. Archives of Agronomy and Soil Science, v. 0, n. 0, p. 1-14, 7 nov. 2016.

$\mathrm{XU}, \mathrm{S}$. An approach to analyzing the intensity of the daytime surface urban heat island effect at a local scale. Environmental monitoring and assessment, v. 151, n. 1-4, p. 289-300, abr. 2009.

XU, Y.; QIN, Z.; WAN, H. Spatial and Temporal Dynamics of Urban Heat Island and Their Relationship with Land Cover Changes in Urbanization Process: A Case Study in Suzhou, China. Journal of the Indian Society of Remote Sensing, v. 38, n. December 2010, p. 654-663, 12 fev. 2010.

ZHANG, $X$. et al. Estimation of the relationship between vegetation patches and urban land surface temperature with remote sensing. International Journal of Remote Sensing, v. 30, n. 8, p. 2105-2118, 20 abr. 2009.

ZHAO, Z. et al. Exploring spatially variable relationships between NDVI and climatic factors in a transition zone using geographically weighted regression. Theoretical and Applied Climatology, v. 120, n. 3-4, p. 507-519, 12 maio 2015.

ZOULIA, I.; SANTAMOURIS, M.; DIMOUDI, A. Monitoring the effect of urban green areas on the heat island in Athens. Environmental monitoring and assessment, v. 156, n. 1-4, p. 275-92, set. 2009. 